\title{
Como os Economistas Discordam: Um Ensaio Metodológico Sobre o "Contexto da Descoberta" em Economia
}

\author{
- Marco ANTONio Ribas CaVAlierl *
}

\begin{abstract}
RESUMO
Este artigo insere-se na área de metodologia das investigações da história do pensamento econômico, isto a partir de uma perspectiva plural, considerando a diversidade de abordagens teóricas como a tônica do conhecimento sobre os fenômenos econômicos. Apresenta-se uma sugestão de método para o estudo do nascimento de escolas do pensamento econômico, aqui chamado de "contexto da descoberta" em economia. Argumenta-se sobre as relações entre a realidade social, específica, histórica e geograficamente, e as teorias e novas abordagens que surgem nesses contextos. A metodologia sugerida envolve desde a caracterização das escolas de pensamento por meio dos conceitos de Kuhn e Lakatos, até o tratamento que deve ser dado à questão do anacronismo, presente em qualquer trabalho de historiografia intelectual. Enfim, um modelo interpretativo é desenhado, com o intuito de utilizá-lo em posteriores pesquisas sobre autores e escolas de pensamento econômico.
\end{abstract}

\section{Palavras-CHAVE}

história do pensamento econômico, metodologia, contexto da descoberta

\begin{abstract}
This article concerns the methodology of investigations about the history of economic thought from a plural perspective, considering the variety of approaches as the strongest feature in the knowledge of economic phenomena. Here it is presented a suggestive methodology to study the birth of schools of thought, what we call the "context of discovery" in economics. We argue about the relations between the social reality, which is historically and geographically specific, and the theories and new approaches that appear in these contexts. The methodology suggested ranges from the schools of thought characterization, by the means of Kuhn and Lakatos categories, to the treatment of anachronism, which is embedded in all intellectual historiography work. As a result, an interpretative model is designed, to be used in future studies about authors and schools of economic thought.
\end{abstract}

\section{KEY WORDS}

history of economic thought, methodology, context of discovery

\section{JEL CLASSIFICATION}

$B 00, B 4 I$

\footnotetext{
* Doutorando do Cedeplar/UFMG, bolsista da CAPES. E-mail: cavalieri@cedeplar.ufmg.br. End. para contato: Av. Sete de Setembro 5345, ap. I I0I, Bairro Batel - Curitiba - PR - CEP 80240-000.

(Recebido em outubro de 2005. Aceito para publicação em julho de 2006).
} 
Foi como se a pintura de Sanzio estivesse viva. Ao bater uma rajada de

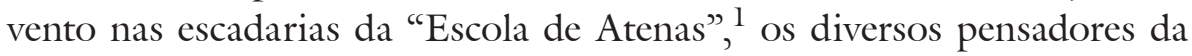
antiguidade começaram a se dividir em grupos. Embora alguns tentassem mediar a desunião que estava ocorrendo, três conjuntos se formaram: em torno de Platão, Heráclito e Arquimedes. De repente surgiram os mais novos, Kant, Schiller, Carlyle, Ranke, Guizot, e estes não hesitaram em se distribuir entre as rodas de conversa já formadas. Sempre aparecia um possível mediador, mas logo que percebia a dificuldade de tal tarefa tomava seu posto em um dos grupos. Tomaram cada vez mais distância uns dos outros, até que só puderam falar entre si.

Foi desse modo que Wilhelm Dilthey (1833-1911) descreveu seu famoso "pesadelo" numa palestra em 1903. Disse que lhe ocorreu logo após suas primeiras investigações em torno daquilo que chamou de Weltschaunng, palavra alemã para a expressão visão de mundo. O "pesadelo", diz ele, mostrou-lhe um desencantamento e um alívio. Isto porque as visões de mundo, que parecem incompatíveis e parciais, têm ao mesmo tempo a virtude de iluminar com cada forma de pensar um elemento próprio da verdade.

\section{INTRODUÇÃO}

A variedade de correntes de pensamento na teoria econômica é um convite à reflexão para qualquer interessado em filosofia da ciência. É também motivadora para aqueles economistas que podem ser classificados como relativistas por uns, mas pluralistas por outros. Desvendar quais foram os "ventos" que dirigiram homens, de diferentes épocas e lugares, a pensar os fenômenos econômicos como eles pensaram, é uma das tarefas mais interessantes que se coloca ao pesquisador da história dessa disciplina. Isto não só para se conhecer "o suor e as lágrimas" que construíram a economia, mas principalmente para reconhecer que a pluralidade é a tônica do conhecimento humano sobre os aspectos econômicos da vida. Não há como praticar economia sem considerar legítimas as diversas visões de mundo, com diferenças fundamentais nos modos de pensar e, mais ainda, sem que o estudioso reconheça-se ele próprio também como objeto de seu estudo.

1 "A Escola de Atenas" é uma pintura concluída em 1509 pelo famoso renascentista Rafael Sanzio (14831520). Ela retrata filósofos da Grécia antiga reunidos em uma escadaria. Alguns dos pensadores retratados são Platão (427-347 a.C.), Aristóteles (384-322 a.C.), Heráclito (544-484 a.C.), Arquimedes (287-212 a.C.), Epicuro (341-270 a.C.), Xenofonte (430-355 a.C.) e Diógenes (404-323 a.C.). 
Neste sentido, este trabalho busca apreender os aspectos metodológicos da pesquisa em história do pensamento econômico, propondo um modelo interpretativo, um protocolo de leitura do que chamaremos de "contexto da descoberta" em economia. Esta expressão deseja fazer referência às inovações teóricas e metodológicas que supostamente caracterizam o surgimento de uma abordagem nova e específica em economia. As proposições que são vistas como novidades trazidas pela economia clássica, pelo marxismo e pelo historicismo, pelo neoclassicismo, pela abordagem austríaca do século XX e pelo institucionalismo caracterizam essas "descobertas". Nosso objetivo, então, é desvelar as motivações intelectuais que levam os economistas a proporem novas abordagens, a quererem substituir no todo ou em parte o saber econômico que conheciam, a pensarem a economia de um ponto de vista diferente e específico.

Afora os acidentes pessoais e os tipos psicológicos de cada um dos pioneiros das escolas de pensamento econômico, sustentamos que novas idéias surgem muito em função dos diferentes loci dos pensadores econômicos no espaço geográfico e no tempo histórico. É peculiar a um lugar, uma ou mais visões de mundo, em relação a determinada realidade social em que os pensadores estão inseridos. Argumentaremos a seguir que não há como evitar que reflexões sobre economia sofram, ou se beneficiem, desse tipo de influências. Há ainda que se considerar modos característicos de se pensar a ciência, fôrmas, moldes nos quais o conhecimento se encaixa, e que são aquilo que Foucault (1989) chamou de condições de possibilidade do conhecimento de uma época, ou episteme, ${ }^{2}$ conceito que ajuda muito na elaboração de um desvio do anacronismo, que embora esteja sempre presente em estudos históricos, pode ser mitigado em certa medida. ${ }^{3}$

Enfim, recorrendo a diversos filósofos e economistas, procuramos formar uma rede de categorias e conceitos que permita não só compreender o surgimento das novas idéias econômicas, mas também entendê-las como derivadas de determinados períodos históricos. Pretendemos, então, delinear algo como um modelo interpretativo geral, que oriente a leitura dos pioneiros das escolas de pensamento, prestando atenção aos entornos nos quais suas idéias frutificaram.

A seção que se segue a essa introdução discute o que é entendido aqui como "contexto da descoberta" em economia, isto principalmente rejeitando a visão de Popper, que argumenta em favor da impossibilidade de se estudar esse momento do fazer ciência de forma estruturada. Depois, os pensamentos de Kuhn e Lakatos são confrontados

2 A palavra episteme, grego, segundo Peters (1983), significa: 1) conhecimento verdadeiro e científico (o oposto de doxa) ; 2) Corpo de conhecimento organizado numa ciência; 3) Conhecimento teorético (o oposto de Praktike e Poiétika). O uso que Foucault dá a essa antiga expressão ficará claro numa das seções seguintes.

3 A metodologia proposta aqui procura construir um modelo que permita se aproximar daquilo que Blaug (2001) chama de reconstrução histórica, em oposição às reconstruções puramente "racionais". 
com a realidade da pesquisa em economia, procurando superá-los naquilo em que não se coadunam com a disciplina em foco. Na terceira seção apresentamos uma categoria da pesquisa em filosofia da ciência que será de grande auxílio na elaboração do modelo interpretativo proposto: o de thematas. Enfim, antes de traçarmos as conclusões, delinearemos o modelo propriamente dito, prestando atenção principalmente ao problema do anacronismo, sugerindo os meios pelos quais ele pode ser atenuado.

\section{O “CONTEXTO DA DESCOBERTA” EM ECONOMIA}

A gana por dividir o mundo do conhecimento em dualismos rígidos, ciência e não ciência, proposições com e sem significado, analíticas e sintéticas, tem seu ápice nos primeiros estudos do antigo Círculo de Viena. ${ }^{4}$ A influência desse modo de pensar, como parte da filosofia debruçada sobre o científico, vai atingir também o pensamento de Karl Popper (1902-1994). Esse autor sustentava, veementemente, uma dicotomia que nos interessa contestar aqui: a que demarca a fronteira entre os chamados contextos da descoberta e da justificação. Seu mais popular livro, "A Lógica da Descoberta Cientifica", traz já no primeiro capítulo o clamor pelo que ele chama de eliminação do psicologismo. Em seus dizeres:

"The initial stage, the act of conceiving or inventing a new theory, seems
to me neither to call for logical analysis nor to be susceptible of it. The
question how it happens that a new idea occurs to a man - whether it is
a musical theme, a dramatic conflict, or a scientific theory - may be of
a great interest to empirical psychology; but is irrelevant to the logical
analysis of scientific knowledge. This latter is concerned not with ques-
tions of fact (Kant's quid fact), but only with questions of justification
or validity (Kant's quid juris)." (Popper, 1968 [1959], p. 31).

Para o estudioso do pensamento econômico parece muito difícil que a separação proposta por Popper possa se sustentar. ${ }^{5}$ Primeiro, porque a relevância do contexto em que as idéias dos economistas surgem "salta aos olhos" a partir dos problemas que os preocupam, e em segundo lugar porque o momento de criação, o "ter idéias" em economia, não parece um processo plenamente irracional e movido somente por uma intuição completamente subjetiva. De Marchi (1992), num volume que explora o estado da metodologia da economia após o chamado "intervalo popperiano", parece

4 O Círculo de Viena, grupo de intelectuais que refletiam sobre a ciência no início do século XX, pretendia purgá-la de toda metafísica. O conhecimento significante para eles era apenas aquele que poderia ser deduzido ou provado empiricamente. Reduziam também toda a filosofia a essa tarefa, na qual não obtiveram muito sucesso.

5 Thomas Kuhn, de quem falaremos adiante neste texto, também contestava a rigidez da dicotomia defendida por Popper. 
esposar o mesmo argumento que queremos sustentar. Refletindo sobre as múltiplas facetas do pensamento de Popper, e considerando a conseqüente pluralidade de abordagens surgida a partir de suas idéias sobre metodologia da economia, De Marchi (1992, p. 6) escreve:

"Popper cannot be blamed for this misapplication of his methodology by some practicing economists. ${ }^{6}$ Nonetheless - getting at last to the reasons I said would presently be given - following him becomes problematic if it is maintained, as Popper does maintain, that the social, cultural, language - and communication - related aspects of the production of knowledge by real live scientists are in a category that is quite distinct from the end product, 'objective knowledge'?.

Os problemas sobre os quais os economistas focam seus esforços analíticos, como foi dito acima, têm claramente algo de externo a uma suposta lógica pura, interna apenas aos desenvolvimentos teóricos. O maior exemplo disso, como colocado na maioria dos manuais de História do Pensamento Econômico, é o surgimento da "Teoria Geral do Emprego, do Juro e da Moeda", de Keynes (1982 [1936]), ocorrida no contexto da crise mundial dos anos 1930. Para além desse exemplo, autores que poderiam ser vistos como cientistas devotados inteiramente à lógica interna de sua ciência, trabalhando isolados do mundo exterior, também se prestam a esse tipo de considerações geralmente associadas a Keynes. León Walras é um exemplo disto, como pode ser visto na análise de Paula (2002). ${ }^{8}$ Dessa maneira, naquela perspectiva popperiana, ao admitir a separação forte entre contexto da descoberta e da justificação, e a impossibilidade de um estudo racional do primeiro, estaríamos muito provavelmente desprezando algo de extrema importância para a apreciação das diferentes teorias econômicas. Backhouse (1998, p. 78), um declarado adepto das idéias de Lakatos, portanto insuspeito de uma falta de tolerância com o pensamento de Popper, sintetiza o que está sendo dito aqui. Primeiro, os estudiosos do pensamento econômico estariam alijados de uma importante fonte de elementos úteis para o seu trabalho, caso o contexto da descoberta fosse totalmente desprezado. Segundo, esses elementos presentes no "criar ciência" são de grande valia para a avaliação das diversas correntes de ideários econômicos, uma vez que se pode dizer que há path-dependence, nos termos dos próprios economistas, sobre os desenvolvimentos posteriores a uma idéia que funda uma corrente de pensamento.

6 É famosa a tese de que os economistas seriam "falsificacionistas inócuos", pois defenderiam tal método sem contudo prestar atenção às suas conseqüências. Recusariam-se a rejeitar teorias falsificadas pela empiria. Ver sobre isto Blaug (1993).

7 A ênfase em negrito não consta no texto original.

8 Falando sobre o Journal des Économistes, publicação do século XIX com clara inclinação liberal-conservadora, e a participação de Walras nela, diz Paula (2002, p. 127): "Foi nessa revista que León Walras iniciou sua carreira de economista, e isso tem vários significados: ele encarnou, talvez inexcedivelmente, o espírito da revista - suas contribuições buscaram combinar a análise dos problemas econômicos, a partir do "espirito geométrico", com um explicito engajamento político ideológico cujo sentido é responder ao desafio socialista mediante reformas sociais compativeis com o capitalismo." 
E, por último, porque a dificuldade em se responder algumas questóes filosóficas, como as relacionadas ao contexto da descoberta, não as desqualificam como perguntas importantes. Este obstáculo deve ser ultrapassado, mesmo que seja mais difícil que os outros.

A distinção entre os dois contextos, o da descoberta e o da justificação, deve ser então mantida como uma distinção de ruptura, ou seja, a descoberta, do ponto de vista adotado neste texto, significaria a proposição de um pensamento econômico novo em sua forma inicial, tal como o equilíbrio geral walrasiano, que deságua na atual corrente domina nte, ou o institucionalismo vebleniano, precursor da economia institucionalista e da evolucionária. A sugestão é que o contexto da descoberta seja um termo que se refere às primeiras proposições, que acabam resultando no surgimento de uma escola de pensamento econômico. Não faz sentido mantê-lo como um corte no que interessa ou não à filosofia da ciência.

Nessa lógica, chamada a atenção para a importância que deve ter esse momento de descoberta na reflexão sobre ciência econômica, torna-se necessário estabelecer as condições de possibilidade de um estudo racional desse mesmo objeto. Mäki (1992) faz sobre isso uma preciosa sugestão.

Os estudos da sociologia da ciência, tais como os desenvolvidos por Bloor (1976), Knorr-Cetina (1981), Whitley (1984) e Loasby (1986), entre outros, têm revelado a possibilidade de se estabelecer uma relação entre a realidade do objeto de estudo, externo à pura lógica interna de uma ciência, e as descobertas e proposições de novas idéias. Uma das conclusões de Mäki (1992, p. 90) ao procurar conseqüências desses estudos de sociologia da ciência é:
"One particular doctrine of Popperian epistemology that threatens to be undermined [by the sociology of science] can be separately mentioned: namely, the distinction between the context of discovery and the context of justification. For Popper, only the latter is characterized by systematic rationality, while the discovery process is open to various nonrational influences. The workings of which cannot be systematized philosophically but should be studied by sociology, psychology, even political science. This distinction, with all epistemological burdens it is supposed to carry, gets blurred by the findings of the sociologists [of science].”

Feita essa observação, parece possível estudar o contexto da descoberta encontrando o que há de comum nesse fenômeno de proposição de novas abordagens. Deixa-se de lado a idéia de que ao olhar esse momento do fazer científico só é factível uma 
descrição de acidentes meramente pessoais. É, então, o estudo da interação entre o ambiente social e as idéias propostas que abre esse caminho.

Neste sentido, os argumentos que serão utilizados no presente texto guardam semelhança com as idéias dos estudiosos da Escola de Edimburgo, o chamado programa forte de sociologia da ciência. Barnes (1974), Bloor (1976) e Shapin (1982) podem ser considerados como autores do núcleo duro desse conjunto de pensamentos acerca da relação entre o ambiente social e o fazer ciência. ${ }^{9} \mathrm{O}$ condicionamento social da ciência, na visão dos teóricos de Edimburgo, se dá numa via causal, do contexto social para o conhecimento científico. As partes metafísicas das propostas teóricas, ou o que trataremos adiante como thematas, nas palavras de Holton (1979, 1988), são vistas como os principais atratores de influência social em ciência. Nesses princípios convencionados, não passíveis de prova empírica ou dedução lógica, repousam conteúdos causados pelos interesses e estruturas sociais. Argumentos como o da existência de equilíbrio nos fenômenos econômicos, utilizado por parte do mainstream da disciplina, seriam então derivados de estruturas sociais que condicionariam, de forma causal, a adoção de tal hipótese.

É importante notar aqui a causação suposta na sociologia da ciência do programa forte de Edimburgo. Nas teses que se apresentarão neste artigo o argumento não é de causação, e sim de restrição. Esta é a diferença essencial com os adeptos do programa forte. Mäki (1992, p. 72) nota muito bem o problema envolvido em teses de causação do contexto social em direção à ciência. Ele escreve:

"It may well be that there is some sort of loose correlation or analogy between some social facts and some scientific theories that protagonists of the Edinburgh program see as being related to one another. It is, however, much more ambitious and demanding to argue that social interests and structures can causally generate the contents of theories and the involved metaphysical presuppositions held by scientists. (...) A successful argument for the existence of a genuinely causal velation would have to indicate the existence and functioning of a mediating mechanism that would make possible for the cause to produce the effect."

Sem a especificação de um mecanismo de causação é ilegítimo dizer que sendo $p_{1}, \ldots, p_{n}$ um conjunto de premissas, que representariam estruturas e interesses contextualmente sociais no caso em tela, sua conjunção implica um resultado dado. Simbolicamente: $p_{1} \wedge \ldots \wedge p_{n} \rightarrow q$, sendo este último um conseqüente elemento de teoria científica. Nosso argumento é mais fraco: $q$ seria um conjunto de proposições científicas, $q=\left\{q_{1}, \ldots, q_{m}\right\}$. Este conjunto, suposto finito, conteria as teorias científicas que seriam

9 Mäki (1992) faz uma interessante síntese dessas e outras idéias da sociologia da ciência. 
capazes de surgir em um determinado ambiente social. Reforçando: nesse condicionamento social da ciência econômica não há um mecanismo de causação que determina essa relação biunívoca entre realidade social e as teorias científicas, apenas restrição. Com isto se quer marcar a posição de que não só operam outros fatores no contexto da descoberta, como existem também elementos, como queria Popper para todos eles, que não se prestam a um estudo analítico ou formal. E, o mais importante: ao se argumentar em favor da tese da restrição, não estamos procurando um mecanismo causal forte, mas somente exigindo que o pensamento econômico seja "fillho" de seu tempo, não anacrônico, em suma.

Porém, antes que coloquemos o modelo interpretativo propriamente dito, é interessante considerar duas filosofias da ciência que tiveram largo apelo entre os estudiosos do método em economia: a de Thomas Kuhn e a de Imre Lakatos. Desta discussão surgirão elementos úteis para a tarefa delineada na introdução.

\section{AS FILOSOFIAS DA CIÊNCIA DE KUHN E LAKATOS E A ECONOMIA}

Apesar das idéias de Kuhn (2003 [1962]) e Lakatos (1970) serem filosofias pensadas a partir das ciências naturais, seu apelo aos economistas foi e continua sendo forte. Um reflexo disso é que essa discussão está sempre presente nos "manuais" que procuram discutir a metodologia da economia. (Blaug, 1993 [1980]; Caldwell, 1982; Hands, 2001). E desde o trabalho pioneiro de Coats (1969), utilizando o ferramental kuhniano, e de Latsis (1976), com o uso de Lakatos, os especialistas em método na economia criticam e superam vários aspectos das idéias desses dois filósofos. Essas discussões são motivadas pelo mesmo ímpeto que nos move no restante desta seção: apresentar críticas sobre aquilo que parece inadequado para a ciência econômica, e tirar proveito de certas categorias propostas por esses autores, que parecem razoáveis para a disciplina em foco.

\section{Thomas Kuhn: Paradigmas, Protociências e Monismo Metodológico}

Após as críticas recebidas em relação à primeira edição de "A Estrutura das Revoluções Científicas" (ERC), publicada em 1962, Kuhn revisa seu conceito-chave - o de paradigma - num posfácio que veio ao conhecimento do público em $1970 .{ }^{10} \mathrm{Nessa}$ revisão ele procura distinguir dois elementos que constituiriam um paradigma. $\mathrm{O}$ primeiro compreenderia três subconjuntos de instrumentos da construção científica: (1) as generalizações simbólicas, que abrangem as fórmulas e leis formalizadas, ver-

10 A crítica que parece ter suscitado a revisão de Thomas Kuhn é a de Margaret Mastermann (1970), que encontra vinte e dois significados diferentes para a palavra paradigma na primeira edição da ERC. 
bal ou matematicamente; (2) as proposições de caráter metafísico; e (3) os valores e as normas esposados por um conjunto de cientistas, tais como acuidade, beleza, simplicidade, formalismo etc. Por outro lado, um paradigma também envolve os exemplares, que são os tipos de questões e respostas que podem demonstrar para um iniciante como se dá a sua articulação, ou seja, como praticar a ciência de acordo com a comunidade que o compartilha. Esse segundo elemento ensina como praticar a ciência normal, que nos termos de Kuhn (2003, [1970], p. 44) é: "[a] tentativa de forçar a natureza a encaixar-se dentro dos limites preestabelecidos e relativamente inflexíveis fornecidos pelo paradigma."

É comum, portanto, notar que escolas de pensamento econômico, termo comum entre economistas, podem ser vistas como paradigmas. Dow (1996, p. 31-32), a mais fiel depositária do kuhnianismo entre os estudiosos do método em economia, nota isso de forma muito clara. Viera e Fernández (2004, p. 9) também percebem a adequação da idéia de paradigma para a economia, isso principalmente em relação à existência de exemplares, difundidos nos manuais das subdisciplinas que os economistas estudam - microeconomia, macroeconomia, economia industrial, internacional etc. Mas, apesar dessa conformidade observável entre as idéias de Kuhn e a realidade da prática científica em economia, duas críticas são sempre recolocadas. Earp (1996, p. 60) sintetiza-as da seguinte maneira:

"Para adotar as idéias de Kubn no campo da economia teríamos que optar entre (i) considerar a economia como pré-cientifica e prosseguir no caminho kubniano, ou (ii) tentar relaxar seu conceito de paradigma, afirmando que a convivência de diversos destes é uma característica das ciências sociais. A segunda dessas alternativas é a mais comum. Na verdade o que se observa é a generalização de uma espécie de "kubnianismo vulgar" no seio da linguagem comum dos cientistas, em que a idéia de paradigma é aplicada a qualquer conjunto de noções legitimadas por um subconjunto da comunidade."

Essa é uma leitura muito comum do autor da ERC. Ele então sugeriria que ciências que têm seu objeto investigado por mais de um paradigma estariam num estágio précientífico, seriam protociências. Contudo, a interpretação rígida sugerida por Earp não parece condizer com as idéias revistas de Kuhn, constantes no posfácio acima mencionado. Segundo ele:

"A natureza dessa transição à maturidade merece uma discussão mais ampla do que a recebida neste livro, especialmente por parte daqueles interessados no desenvolvimento das ciências sociais contemporáneas. Indicar que a transição não precisa (atualmente penso que não deveria) 
estar associada com a primeira aquisição de um paradigma pode ser útil a essa discussão. (...) O que muda com a transição à maturidade não é a presença de um paradigma, mas antes a sua natureza. Somente depois da transição é possível a pesquisa normal orientada para a resolução de quebra-cabeças."11 (Kuhn, 2003 [1970], p. 225).

O que Kuhn parece afirmar, depois de reconsiderar a rigidez de sua idéia a respeito das disciplinas científicas que convivem com mais de um paradigma, é que essa situação não é a mais comum, embora exista, especialmente nas ciências sociais. A prática da "normalidade" é então o critério para separar as protociências daquelas maduras. No entanto, ainda escapa a Kuhn o fato de que existem ciências que convivem, em situação permanente, com as discussões de fundamentos, de métodos, de valores, e com a prática dentro dos limites paradigmáticos.

E isso é o que parece ocorrer na economia. É possível, a partir da literatura especializada, dizer que marxistas, neoclássicos, institucionalistas e até mesmo no passado os historicistas sustentaram discussões acerca de fundamentos, bem como procuraram articular o objeto de estudo por meio de seu paradigma. Por exemplo, debates acalorados como o famoso methodenstreit, que envolveu em fins do século XIX um neoclássico, Carl Menger, e um historicista, Gustav Von Schmoller, discutiam o método da economia, os fundamentos. Ao mesmo tempo eram levadas a cabo articulações teóricas, em bases dedutivas, a partir das idéias de utilidade marginal, presentes em Menger. Eram também realizadas pesquisas empíricas sobre a história da economia européia, nas bases sugeridas pelos predecessores de Schmoller. A economia parece conviver não só com vários paradigmas conflitantes, o que é admitido por Kuhn, mas também com discussões de fundamentos simultâneas às "resoluções de quebracabeças" ${ }^{12}$ Porém, ao levantar as diferenças entre as teses de Kuhn e a prática real dos economistas, é preciso tomar cuidado para que nem todas as sugestões "sejam jogadas fora junto com a água do banho". A idéia de se utilizar os paradigmas como unidades de análise, em vez de teorias isoladas, deve ser considerada a grande contribuição de Kuhn. Isto especialmente para os economistas, que trabalham sob a coexistência de várias escolas de pensamento.

11 A ênfase em negrito não consta no texto original.

12 A "resolução de quebra-cabeças" é uma figura de linguagem muito utilizada por Kuhn para se referir à prática da ciência normal. 


\section{Imre Lakatos: O Demarcacionismo e os Programas de Pesquisas Cientificas}

A solução de Lakatos, para restabelecer a filosofia da ciência em bases demarcacionistas, ${ }^{13}$ após o ataque da ERC, mescla aspectos das idéias kuhnianas com uma elaboração mais complexificada do falsificacionismo. A idéia de paradigma se transmuta na de programa de pesquisa científica (PPC), que nada mais é que "uma sucessão de teorias e não uma dada teoria que é apreciada como cientifica ou não científica." (Lakatos, 1970, p. 132). ${ }^{14}$ Nessa lógica, Lakatos também reconhece conjuntos de teorias com afinidades claras, nos moldes sugeridos pelo conceito-chave kuhniano, e esses grupos de teorias passam a ser as unidades primordiais de análise. Por outro lado, tais séries de teorias devem ser julgadas não com base num falsificacionismo ingênuo, que Kuhn (2003 [1970], p. 28) percebe como não adaptado à história da ciência, mas numa versão mais sofisticada dele. O critério passa a ser histórico. Os PPCs, que em economia poderiam ser os mais diversos possíveis, ${ }^{15}$ seriam classificados como degenerativos ou progressivos. E essa progressividade pode ser empírica ou teórica. Nesta última, o programa de pesquisa consegue articular novas questóes, explicando e predizendo, além de incorporar problemas sugeridos por programas rivais. E ele será empiricamente progressivo se esses avanços teóricos forem corroborados pela realidade sensível. Não são degenerativos aqueles programas que são ao mesmo tempo teórica e empiricamente progressivos, e estarão do lado interno da linha demarcatória aqueles que ao menos forem teoricamente progressivos. (Lakatos, 1970, p. 118).

Porém o exame dos programas nesses termos só é possível em retrospecto. Parece que nesse ponto Lakatos procura incorporar o argumento de Kuhn, no qual há uma certa tenacidade dos cientistas em relação ao seu programa de pesquisa, ou paradigma, mesmo ante reiteradas falsificaçôes no sentido ingênuo do termo. Lakatos (1970, p. 119-118) aduz:

\section{"Contrary to naive falsificationism, no experiment, experimental re- port, observation statement or well-corroborated low level falsifying bypothesis alone can lead to falsification. There is no falsification before the emergence of a better theory. But, of course, if falsification}

13 Essa expressão é utilizada por Isabelle Stengers (2002). Ela abarca nesse conceito as abordagens de Popper e Lakatos, com o pretexto de diferenciá-los dos positivistas lógicos e empiricistas. Popper e Lakatos não estariam preocupados em purgar a ciência de toda a metafísica, reconhecendo a importância desse elemento, mas ainda carregam, como principal mote da empresa filosófica, a necessidade de marcar diferença entre ciência e não ciência por meio de um critério único. Ver Stengers $(2002$, p. $38)$.

14 No original: "...a succession of theories and not one given theory which is appraised as scientific or pseudo-scientific."

15 Backhouse (1998, p. 41), um advogado da metodologia lakatosiana entre os metodólogos da economia, nota que o conceito de programa de pesquisa científica pode ser aplicado tanto a grandes tendências do pensamento econômico, tais como o institucionalismo ou o neoclassicismo, como num nível mais específico podemos falar da macroeconomia neowalrasiana ou pós-keynesiana. 


\begin{abstract}
depends on the emergence of better theories, on the invention of theories which anticipate new facts, then falsification is not simply a relation between theory and the empirical basis, but a multiple relation between competing theories, the original 'empirical basis', and the empirical growth resulting from the competition. Falsification can thus be said to have a 'bistorical character'."
\end{abstract}

O problema com essa abordagem é que o critério que tinha uma força imensa em Popper, num suposto falsificacionismo ingênuo, no qual teorias falsificadas devem ser sumariamente descartadas, em Lakatos parece ser deixado a cargo da passagem do tempo. $\mathrm{O}$ corte, isto é, a decisão final sobre a degeneração de um programa, que deve ser tachado de não científico, passa a exigir uma decisão a partir da história, o que indubitavelmente carrega certo grau de arbitrariedade, pois ao historiador compete interpretar, sujeitando o veredicto às suas descobertas, seus lapsos e suas idiossincrasias. Na opinião de Stengers (2002, p. 47): “...o ponto mais importante, aquele que marca aos meus olbos o fim da tradição demarcacionista, ainda é a impossibilidade de se formular explicitamente critérios que informados pelo passado, valessem para o para o presente." Hands (2000) muito habilmente nota que a metodologia da economia, em vista das dificuldades suscitadas pelas filosofias de inspiração demarcacionista, impregnadas de intenção prescritiva, acaba por abandonar a busca de um critério, como queriam Popper e Lakatos.

Diante disso, mesmo reconhecendo que Lakatos não consegue reverter a tendência de abandono às fillosofias da ciência prescritivas iniciada por Kuhn, suas considerações adicionam alguns elementos interessantes aos nossos objetivos. Sua caracterização dos PPCs parece ser útil na medida em que separa seus elementos em duas partes: o núcleo duro e o cinturão protetor.

O núcleo duro de um PPC seria o locus de princípios que estariam no âmago das convenções dos cientistas que o comungam. As proposições contidas nesse núcleo não são contestáveis por uma decisão metodológica dos seus protagonistas. (Lakatos, 1970, p. 133). As regras que evitam o direcionamento do chamado modus tollens ao núcleo duro do programa constituem a sua heurística negativa. ${ }^{16}$ Esses princípios, reunidos nessa parte do programa, têm então um caráter metafísico. Não são discutíveis. É um outro componente do programa que se engalfinha com os dados da realidade: o cinturão protetor. Este é formado por teorias que são elaboradas a partir dos princípios básicos, elementos do núcleo duro, e dirigidos por uma heurística positiva, isto é, um

16 Modus Tollens, do latim, significa modo de negação. É uma estrutura comum de argumento lógico (Alencar, 1992): $p \rightarrow q$ (se $p$, o antecedente, implica $q$, o conseqüente); $\sim q \rightarrow \sim p$ (então se $q$ é falso $p$ também é). 
conjunto de regras que contém as diretrizes sobre quais questões devem ser feitas e como elas devem ser respondidas. Lakatos (1970, p. 135) explica:

\section{"The negative heuristic specifies the 'hard core' of the programme which is 'irrefutable' by the methodological decision of its protagonists; the positive heuristic consists of a partially articulated set of suggestions or hints on how to change, develop the 'refutable variants' of the research program- me, how to modify, sophisticate, the 'refutable' protective belt."}

Assim, do mesmo modo que fizemos com Kuhn, rejeitamos um elemento caro a Lakatos: a possibilidade de se estabelecer um critério de demarcação entre ciência e não ciência, principalmente porque isso exigiria uma avaliação das escolas de pensamento econômico nessa linha. Mas aceitamos, e enfatizamos, a utilidade de se colocar teorias afins dentro de um conceito "guarda-chuva", que no caso de Kuhn é o paradigma e para Lakatos o PPC.

Aproveitando as idéias de Lakatos, portanto, é útil ter em mente a separação entre os elementos de um PPC: o núcleo duro e o cinturão protetor. É inegável que os economistas se sintam atraídos por uma visão que, embora seja rígida, confere um alto grau de organização às séries de teorias a se considerar. O uso dos conceitos de núcleo duro, heurísticas e cinturão protetor não deve ser dependente dos elementos mais contestáveis da metodologia lakatosiana discutidos acima. (Backhouse, 1998, p. 87). Porém, inúmeros problemas surgem ao se tentar a aplicação estanque, por exemplo, do conceito de núcleo duro. PPCs que se entrecruzam, princípios fundamentais que são esquecidos, substituídos e adicionados, fronteiras nebulosas entre proposiçôes pertencentes a cada um dos dois conjuntos e desacordos entre cientistas dentro de uma série de teorias razoavelmente coesas. Mas, como nota Backhouse (1998, p. 8788), é possível encarar a filosofia de Lakatos de forma mais abrangente, relaxando o que tem se passado como uma separação extremamente rígida, percebendo que aquele autor põe em evidência a existência de regras metodológicas. Desse modo, pode-se distinguir heurísticas, tanto negativas como positivas, como parte do núcleo duro de um programa de pesquisa, em conjunto com suas proposições fundamentais.

\section{Sintese: O Que Fica de Kubn e Lakatos?}

Neste ponto é interessante sumariar a discussão acima, com a motivação de notar o que será utilizado adiante das idéias expostas até aqui. Primeiro, rejeitamos em Kuhn e Lakatos duas teses:

(1) A idéia de Kuhn de que há uma separação entre momentos de ciência normal e revolucionária, isto é, entre a pesquisa dentro do arcabouço fornecido por um 
paradigma e a discussão de fundamentos. O que parece ser a norma em ciência econômica é a convivência entre essas formas de construção do científico;

(2) Em Lakatos não parece ser adequada a idéia de decretar a degeneração definitiva, ou colocar fora da linha fronteiriça entre a ciência e a não ciência algum PPC. Essa decisão seria carregada de um enorme grau de arbitrariedade. Em economia é comum se resgatar pensamentos de cientistas que estavam "adormecidos". Além disso, a tenacidade aos diversos PPCs em economia parece ser de uma força incomum às ciências naturais. Desse modo, como foi chamada a atenção por Hands (2000), a metodologia da economia enveredou nos últimos anos por um caminho que em larga medida despreza o caráter prescritivo e demarcacionista de filosofias como a de Lakatos.

O que é mais importante, contudo, é aproveitar alguns elementos trazidos por essas importantes proposiçôes filosóficas. Dois pontos são os mais interessantes no tocante ao que será discutido adiante.

(1) A idéia de Kuhn de se avaliar paradigmas, que em Lakatos transforma-se em PPC, é o que queremos reter com bastante ênfase. É natural para os economistas a visão de que sua ciência é dividida em diversas formas de abordar seu objeto. Comumente chamam-se esses diferentes approaches de escolas de pensamento. Pensar em conjuntos de teorias com afinidades metodológicas como unidades de avaliação para a reflexão sobre ciência parece ter sido a grande contribuição de Kuhn, ao menos do ponto de vista do economista;

(2) Por sua vez, Lakatos apresenta uma descrição mais adequada aos nossos propósitos dos elementos de um paradigma, escola ou PPC. As separações sugeridas por Kuhn, na matriz disciplinar que engloba generalizações simbólicas, proposições metafísicas e normas e valores, e por Lakatos com seus núcleos duros e cinturões protetores, não devem ser vistas como mutuamente excludentes. Mas o método de estudo da história do pensamento econômico que será sugerido aqui fará uso do conceito de núcleo duro. Isto, no sentido mais lato, como na proposta de Backhouse (1998). Buscaremos, então, nas escolas de pensamento econômico, heurísticas positivas e negativas, bem como os princípios formadores de determinado ideário econômico. E isto deve ser feito, segundo a sugestão apresentada aqui, por meio do modelo interpretativo ou protocolo de leitura. 


\section{IMAGINAÇÃO CIENTÍFICA: O CONCEITO DE THEMATAS}

Recentemente o trabalho de Holton (1979, 1988), especialista em história da ciência, vem sendo utilizado por economistas para discutir e caracterizar alguns aspectos dos PPCs em economia. (Viskovatoff, 2003; Peacock, 2000, 2004). A categoria principal proposta por esse autor é a de themata, um tipo peculiar de princípio ou proposição científica.

A mais relevante contribuição de Holton (1988, passim) é assinalar como errônea a concepção que se encontra no famoso "dilema" de Hume (1711-1776). ${ }^{17}$ Ele defendia a idéia de que todo o conhecimento científico relevante era formado por proposições de natureza sintética ou analítica. As primeiras seriam derivadas da observação de dados da realidade e as últimas deduzidas, lógica ou matematicamente, a partir de postulados mais gerais. $\mathrm{O}$ autor em foco contesta essa dicotomia, assinalando a presença na ciência de elementos que fogem ao encaixe nessas duas categorias. Com isso pretende argumentar contra uma série de filósofos, que com algumas variantes esposam a tese de Hume. ${ }^{18}$ Em uma explicitamente imperfeita, porém bem colocada, analogia com um plano cartesiano, Holton (1988, passim) nota que segundo Hume as proposições científicas podiam ser localizadas num espaço bidimensional, sendo, por exemplo, o eixo y o dos componentes sintéticos, ou fenomênicos, enquanto no eixo $x$ estariam os analíticos. Ele chama esse plano de contingente. Mas, segundo Holton (1988, p. 13):

"If, however, we want to make it [the analysis of the scientific creation, or the psychological and sociological elements] part of our business is to understand how new discoveries are made and how scientific ideas meet with acceptance or rejection, it is necessary at this point - to return to our analogy - to define a third dimension, or z-axis, perpendicular to the $x$-and $y$-axes of the contingent plane. It is the dimension of themata, of those fundamental preconceptions of a stable and widely diffused kind that are not resolvable into or derivable from observation and analytic ratiocination. They are often found in the initial or continuing motivation of the scientist's actual work, and also in the end product to which his works reaches out."

É notável, ao longo da história da ciência, a conformidade dessa observação. As chamadas thematas seriam então os componentes metafísicos de uma dada teoria, ou série delas, que formariam uma raiz sobre a qual se erguem as proposições que seriam as

17 O que foi aqui traduzido como "dilema de Hume" é conhecido em inglês como "Humès fork".

18 Entre eles pode-se citar: Comte (1798-1857), Mach (1838-1916), Mill (1806-1873), bem como a maioria dos participantes do Círculo de Viena. 
únicas relevantes para Hume. Holton $(1979$, p. 13) diz que com essas thematas são formados modelos de imaginação científica, nos quais se encaixam as mais diferentes formas de proposições e teorias. Algumas thematas têm sido recorrentes no pensamento dos cientistas, tais como a existência de uma correspondência micro-macrocosmo, as interpretações organicistas e mecanísticas, motivações teleológicas, a idéia de que "o livro do Universo foi escrito em matemática", atribuída a Galileu (1564-1642), e a oposição permanência-mutação, que opunha as filosofias de Parmênides de Eléia (530-460 a.C.) e Heráclito de Éfeso (540-470 a.C.). (Holton, 1988, p. 14). Este último exemplo marca, como sugere esse autor, a existência de thematas e antithematas, isto é, geralmente um elemento desse tipo é usado por alguns cientistas, ao mesmo tempo que seu oposto é utilizado por outros. Holton (1988, p. 14) ainda chama a atenção para o fato de que o atomismo talvez seja a themata mais famosa que já foi proposta.

No que diz respeito à teoria econômica, alguns estudos podem ser encarados como à Holton. (Peacock, 2004). Notadamente o trabalho de Lawson (2003), que parece encontrar três thematas aceitas entre os adeptos da economia moderna de fundo neoclássico. Elas seriam: (1) a "teoria econômica" deve ser matemático-dedutiva em sua natureza; (2) a "explicação" consiste em mostrar que os indivíduos otimizam determinada variável e (3) também em encontrar um ponto de equilíbrio dos fenômenos econômicos. Neste exemplo é possível perceber a flexibilidade que o conceito de thematas carrega. Ele pode dizer respeito a uma heurística, que sugere quais são as perguntas e as formas de resposta relevantes, e ao mesmo tempo fazer referência a uma visão de mundo, ou princípio ontológico, como na matematização proposta por Galileu. No estudo de Lawson fica claro que são os elementos formalizáveis dos fenômenos econômicos os mais importantes do ponto de vista neoclássico, como nos diz a themata (1). E mais ainda, além das perguntas e respostas serem formuladas em linguagem matemática, na maioria das vezes as respostas devem ter a forma de solução de um problema de otimização e equilíbrio, thematas (2) e (3).

Queremos ressaltar aqui que nosso modelo interpretativo será construído no intuito de desvelar essas thematas. Isto principalmente em razão da observação já citada de Holton, alertando-nos para a presença desses elementos no momento de criação, ou seja, no que estamos querendo chamar de contexto da descoberta. 


\section{UMA SUGESTÃO DE MODELO INTERPRETATIVO OU PROTOCOLO DE LEITURA}

Tendo feito a discussão acima, resultando disso a observação de que estamos tratando de escolas de pensamento econômico ${ }^{19}$ como algo que pode ser entendido como um paradigma ou PPC, e de que estaremos buscando as thematas e as heurísticas de pesquisa que surgem na inauguração dessas vertentes de ciência econômica, podemos proceder à construção do modelo interpretativo sugerido.

Para cumprir tal objetivo serão necessários três passos. O primeiro é discutir o anacronismo ao qual estamos sujeitos numa análise de pensamentos de outras épocas e lugares, que não os do próprio pesquisador. É mister admitir que ele sempre estará presente no trabalho historiográfico, mas deve-se contorná-lo no que for possível. Os dois passos seguintes consistem em discutir duas vias pelas quais isso pode ser feito, isto é, considerando as diversas visões de mundo e epistemes.

\section{O Problema do Anacronismo}

Na seção que segue à introdução desse texto já foi discutida a relação entre o meio social e a ciência. Marcamos que a posição dos teóricos de Edimburgo parece um pouco forte demais, parodiando o próprio rótulo dessa corrente de pensamento escocesa. Mas não podemos fugir às considerações sobre a mediação entre a realidade contextual e a produção científica. Isto fica mais patente ao se estudar ciências sociais, pois como dizia o filósofo Wilhelm Dilthey (1833-1911), é das ciências do espírito, termo usado por ele para as ciências histórico-sociais, que temos consciência imediata. Somos ao mesmo tempo objeto e sujeito desse tipo de conhecimento. Estamos presos à realidade que nos cerca, mesmo ao se tecer considerações sobre idéias nascidas em outros tempos e lugares. Desvencilhar-se dessas amarras, na medida do possível, é tarefa essencial para o estudioso do desenvolvimento de uma disciplina. Evitar o anacronismo, portanto, ainda que não seja plausível que isto se dê por completo.

Paula et al. (2001, p. 4) nos advertem sobre a localização espaço-temporal do pensamento econômico. Dizem eles que as idéias dos economistas são formas também,

19 É preciso notar aqui que o núcleo duro de um determinado PPC, como marca Lakatos, é um conjunto de proposições consensuais, exigindo então que decorra um período de articulação das idéias que apareceram no que chamamos de "descoberta". Contudo, estamos considerando que as primeiras idéias de um pensamento econômico são em geral mantidas nos desenvolvimentos posteriores, pois é razoável admitir isto, dado que estamos fazendo um estudo em retrospecto, isto é, conhecemos quem foram os economistas que deram início às tais escolas. Sabemos que Walras é considerado o precursor da microeconomia mainstream moderna e que Veblen, por exemplo, foi o patrono do institucionalismo. Deste modo, do ponto de vista atual, ou seja, de quem pode observar quais foram as idéias que frutificaram em ciência econômica, é plausível se falar em núcleo duro no "contexto da descoberta", fazendo referência aos elementos que determinados autores pioneiros procuraram ressaltar como fundamentais. 
assim como a literatura, a filosofia e outras manifestações humanas, de "extrinsecação" das diversas formações sociais. Há um desenvolvimento próprio de algo como uma lógica interna aos argumentos, mas mesmo estes não estão plenamente imunes às intersecções com o contexto histórico. As fronteiras entre o que é ou não afetado pelo mundo no qual determinado economista se insere são nebulosas, mas não são inexploráveis. Enfatizando novamente o que foi dito acima, trata-se de admitir que as realidades tornam mais restritas as opções de vias pelas quais o pensamento científico pode enveredar. É exigido, por causa disso, algo como um "mergulho contextual" do pesquisador.

O famoso historiador Lucien Febvre (1959), num trabalho sobre o tempo e a obra do escritor francês Rabelais (1494-1553), faz uma das mais interessantes discussões acerca do anacronismo na historiografia das idéias. Perguntando, e recusando-se a aceitar a tese do senso comum, sobre a possibilidade de se considerar Rabelais como defensor do ateísmo em pleno século XVI, Febvre (1959, p. 122) observa:

"Cada civilización posee un conjunto de utensilios (valga la palabra) mentales; más todavia, a cada época de una misma civilización, a cada progreso, ya de las técnicas ya de las ciencias, que la caracteriza, se remueva ese conjunto de utensilios y se hace algo más desarrollado para algunas aplicaciones y algo menos para otras. $\Upsilon$ se trata de un conjunto de utensilios mentales que esta civilización que esta época determinada no puede asegurar que sea capaz de transmitir integralmente a las civilizaciones $y$ las épocas que le sucederán; es posible que se produzcan mutilaciones, retrocesos, deformaciones importantes; o al contrario, progresos, adelantos, enriquecimientos, nuevas complicaciones e nuevas complejidades. Ese conjunto mental tiene validez para la civilización que supo forjarlo; tiene valor para la época que lo aplica; pero no sirve para toda la eternidad ni para toda la humanidad, ni siquiera para el limitado curso de una evolución interna de civilización."

Febvre conclui que se não é possível afirmar que Rabelais era um escritor católico tradicional, em vista das suas reiteradas críticas e ironias com essa instituição, também não é possível afirmar o contrário, que ele era um "inimigo bem resolvido do catolicismo", um defensor fervoroso do ateísmo. Isto porque, dado o ambiente permeado pela religião, em todas as suas instâncias, cenário típico do século XVI, dificilmente se abririam possibilidades para um escritor que fosse ateu militante. Não se pode estudar Rabelais com os utensílios mentais do século XX, pois os escritos de um ambiente no qual a religião é o centro da vida social não podem ser vistos com os olhos de observadores separados deles por cinco séculos de história. Como já dissemos, ainda que o anacronismo não possa ser eliminado por completo, a tentativa de mitigar seus efeitos, 
no que for possível, é essencial. Fazendo um paralelo com nosso assunto, poderíamos nos perguntar: seria possível para um economista alemão do século XIX não prestar atenção à história, ou à questão regional/nacional? Para responder não podemos prescindir do mesmo esforço empreendido por Febvre, uma tarefa de contextualização.

No que se segue, o modelo de interpretação sugerido propõe duas vias pelas quais o anacronismo pode ser atenuado. A primeira diz respeito à análise do ambiente político e econômico de uma determinada sociedade histórica e geograficamente localizada. A idéia é que a ideologia, ou como poderia ser preferido, dada a suspeita que esse termo carrega atualmente, a visão de mundo, transporta para dentro das teorias econômicas elementos da realidade específica, restringindo-a. Por outro lado, como nos chama a atenção Foucault (1981), existe uma fôrma, um molde intelectual de idéias, isto é, condições de possibilidade, maneiras características de se expressar o conhecimento em cada período histórico. Há uma episteme peculiar a cada época.

\section{Quatro Teses Sobre a Ideologia ou Visão de Mundo}

Houve um tempo no qual debates em torno da questão política na teoria econômica provocavam mais os economistas. Não que a ciência econômica tenha evoluído em direção a um conhecimento mais objetivo, menos carregado de interferências advindas de interesses sociais os mais diversos, mas porque uma pretensa tecnificação do paradigma dominante parece não se beneficiar com discussões desse tipo. Porém, ao se estudar história do pensamento econômico, principalmente o que estamos chamando de contexto da descoberta, é muito difícil não perceber, claramente, os contornos de uma visão de mundo específica nas teorias.

Sendo assim, é importante definir, de início, o que tratamos por ideologia ou visão de mundo. ${ }^{20}$ Primeiro é interessante marcar o caráter metafísico das concepções que se encaixam nessa categoria. Nisto seguimos o que foi ressaltado por Joan Robinson (1964, p. 11):

"A caracteristica principal de uma proposição metafísica é o fato de não poder ser comprovada. Não sabemos em que respeito o mundo seria diferente, se isso não fosse verdade. O mundo seria exatamente o mesmo, exceto que cada um de nós estaria fazendo diferentes ruidos. Nunca poderá provar-se que está errada, pois será pronunciada em cada discussão, na sua própria circularidade; ela protesta ser verdadeira, apenas pela definição de seus próprios termos. (...) Apesar disso os enunciados metafísicos

20 Usaremos os dois termos, de forma alternada, para fazer referência à mesma categoria analítica. 
não deixam de ter conteúdo. Exprimem um ponto de vista e formulam sentimentos que são um guia para a conduta."

Também é importante marcar que a visão de mundo não é somente de caráter político, embora esse seja sem dúvida o fator mais influente. Como na definição de Heilbroner e Milberg (1995, p. 4): "By vision we mean the political hopes and fears, social stereotypes, and value judgments - all unarticulated, as we have said - that infuse all social thought, not through their illegal entry into an otherwise pristine realm, but as psychological, perhaps existential, necessities." Dobb (1973, p. 2) sugere que se pense em termos de uma "filosofia social", "sistema de pensamento global" ou "um conjunto coordenado de crenças e idéias” sobre a sociedade. É esse tipo de definição mais larga que usaremos para o exposto neste ensaio. Neste ponto, ainda, é interessante chamar a atenção para o aspecto plural que as diferentes visóes de mundo conferem ao pensamento econômico. Dow (1996, p. 2) adota a posição segundo a qual é impossível estudar diferentes correntes de ciência econômica sem referência à variedade de escolas, surgidas muito em razão dessa diversidade de visões. E isso nos leva à primeira tese que sustentaremos sobre a ideologia em economia.

Não há como escapar do alcance das visões de mundo. Em qualquer teoria que se tome ela é ubíqua, todos os conhecimentos gerados em economia estão sujeitos às suas influências. Myrdal (1958), que defende o estudo da história do pensamento a partir dos diversos pontos de vista, atribui à variedade de visóes as diferenças entre os pensadores de distintas escolas. Segundo ele:

"There is no way of studying social veality other than from the viewpoint of human ideals. A 'disinterested social science' has never existed and, for logical reasons, cannot exist. The value connotation of our main concepts represents our interest in a matter, gives direction to our thoughts and significance to our inferences... The recognition that our very concepts are value-loaded implies that they cannot be defined except in terms of political valuations." (Myrdal, 1958, p. 1-2).

Schumpeter (1964, p. 63), por sua vez, apesar de separar visão - que ele chama de "ato pré-cognitivo" - e análise através de uma fronteira rígida, nota o seguinte:

"Afora isto [as influências negativas da ideologia para a ciência], entretanto, não poderemos seguir Mannheim através de sua saida de emergência porque aceitamos integralmente a doutrina da ubiquiidade do desvio ideológico e, por isso mesmo, não podemos acreditar que alguns dele se libertem, pois cremos que ao pensarem fazê-lo, estejam realmente embaraçados numa parte viciosa de sen próprio sistema de erros." 
É perceptível a atitude negativa de Schumpeter em relação à presença de influências de coloração ideológica na ciência. Uma postura como essa surge da hipótese de que uma visão de mundo é capaz de distorcer os fatos em favor de determinados objetivos, sejam eles culturais, políticos, econômicos etc. É interessante admitir que tais desvios ocorrem, no sentido de que a prevalência de diversas motivações políticas, por exemplo, possa fazer da ciência social um simples veículo de sua legitimação. Não é razoável negar que isto de fato acontece, mas a visão de mundo também tem um papel positivo. No sentido de ser um guia, como nos falou Joan Robinson na citação acima, e na forma de um reflexo das idéias e da forma de conceber a sociedade em determinada época. Apesar, então, de a ideologia agir como uma "falsa consciência", como queria Hegel, ela tem o papel de situar, de servir de base sobre a qual se erguem as idéias em ciências sociais. Uma vez que ela é ubíqua, e abandonando a visão de que a ciência econômica seja apenas legitimação deste ou daquele sistema de vida social, só resta admitir a pluralidade e a necessidade desse elemento na construção do saber. Compreender que a ideologia tem o papel de levar à economia as crenças políticas, culturais, os hábitos de pensamento, as "esperanças" e "medos" em relação à realidade social, que existem em determinado tempo e lugar, passa pela necessidade de reconhecer sua importância, já que a ciência social deve versar sobre os assuntos que são o conteúdo dessas visões. Além disto, considerando as observações de Feyerabend (1993) sobre a proliferação de teorias, a diversidade de visões e a plural ciência derivada resultam num aumento de conteúdo empírico do conhecimento humano, ou seja, ao enfatizar diferentes aspectos da realidade econômica, as visões ajudariam a ciência na tarefa de cobrir um maior "território" de fenômenos. Essa idéia de que a visão de mundo, ou a ideologia, não tem somente ação negativa sobre a realização da ciência, é a nossa segunda tese.

Agora, mesmo reconhecendo a impossibilidade de se livrar completamente da influência das ideologias, Schumpeter (1964, p. 64-67) propóe que o desenvolvimento de métodos e instrumentais de análise econômica tenha uma história separada, desvinculada das visões de mundo. Ele argumenta a favor da possibilidade de se construir uma narrativa não concernente às políticas econômicas que os antigos pensadores defenderam, pertencentes a uma esfera que ele chama de sistemas de economia política, mas sobre como eles fizeram essas defesas, elementos do conjunto da análise econômica. A defesa do livre comércio pode ser encontrada em Smith de determinada forma e em Ricardo, ou em Hecksher e Ohlin, de outra. Isto é perceptível, há o que podemos chamar de refinamento do instrumental. Mas não se deve admitir que esse instrumental esteja inteiramente desconectado de "atos pré-cognitivos". Dobb (1973, passim) nos fala que ao escolher categorias, ferramentas de obtenção de resultados, a forma de validação desses e uma taxonomia dos elementos observados, o cientista está praticando aquele "ato pré-cognitivo" que Schumpeter descreveu. Dobb (1973, p. 7) diz: 


\begin{abstract}
"In choosing one structure in preference of another, the model-builder is not only providing a scaffolding of framework within human thought can operate, but is laying emphasis upon certain factors and relationships excluding others or casting them into shadows; and in doing so be can be judged to be distorting or illuminating reality, and thus affording an unsound or a sound basis for interpretation or prediction - more likely perhaps he is illuminating some corners or facet of reality, or certain situations that recur, at the same time as he is obscuring, or totally concealing, others. (...) But in the degree that he is influenced by its economic implications - in the degree, that is, to which he is trying to be an economist - its shape and projection will be influenced by his vision of the economic process, and by whatever socio-historical conditions shape and limit his mental picture of social reality."
\end{abstract}

Colocada a impossibilidade de uma separação dos elementos formadores da ciência econômica, em compartimentos uns sujeitos e outros não às influências de visões de mundo, só resta notar que as ideologias que estamos tratando são frutos de tempos e lugares determinados. Essa contextualidade é uma característica forte dessas visões. É natural que as visões que permeiam as idéias dos mais diferentes economistas toquem questões relevantes para os seus entornos sociais. Não estamos querendo dizer que elas fiquem presas e não tenham significação à frente de seu tempo. Mas as condições da reflexão primeira, aquela que embasa o nascimento de um pensamento econômico, são em muito localizadas no contexto histórico dos pensadores. A Alemanha de Marx e List, os Estados Unidos de Veblen, a Grã-Bretanha de Smith, ou mais de um século e meio depois a de Keynes, são as realidades a partir das quais nascem as visões de mundo. Ao observarmos a pluralidade teórica da economia, devemos admitir semelhanças: o papel do estado está destacado em List e Keynes; a mão invisível em Smith e Walras; e as classes em Marx e Veblen, mas cada um constrói a ciência econômica a seu modo, revelando estilos variados, nacionais, ou regionais, e sobretudo históricos. Enfim, nossas quatro teses são:

(1) Existe ubiqüidade da visão de mundo entre os economistas, ou quaisquer cientistas sociais. Não há um pensamento, nesse sentido, mais objetivo que outro. Todos partem de visões particulares e chegam a conclusões diferentes em razão disso;

(2) Embora admitamos o conceito hegeliano de falsa consciência, isto é, a tese de que ideologias provocam distorções nas questões propostas e nas formas de resposta de cada vertente do pensamento econômico, não vemos somente o lado negativo de estarmos presos à necessidade de visões de mundo. Isto tanto pelo argumento de Feyerabend, que destaca o crescimento do conteúdo empírico do conhecimento, dadas as variadas visões e teorias que elas suscitam, como pelo fato de necessitar- 
mos dos pontos de vista como pilares sobre os quais se sustentam as diversas idéias. Eles refletem seu tempo e seus lugares, fazem com que os economistas se dediquem às questões que "importam para alguém”;

(3) Não há como separar, de forma estanque, elementos afetados ou não pela visão de mundo. Tanto as defesas de certas políticas, ou interpretações, como a forma pela qual se faz essas defesas são suscetíveis às influências das ideologias;

(4) Em relação aos três pontos que foram arrolados acima, as visões de mundo são contextuais, surgem em determinada realidade social. Não precisam ficar presas a ela, não se esgotam nas épocas de seus nascimentos, mas transmutam-se, desenvolvem novas formas. Mas sua base é temporal, localizada. As thematas que aparecem nos pensamentos econômicos são seus produtos, são "extrinsecações" dessas visões de mundo, que por sua vez são produtos de realidades da sociedade em que surgem.

\section{Os Lugares da Episteme}

Não só ligado às questões sociais que perpassam o pensamento econômico, por meio daquilo que os economistas arrolados acima vêem como visão de mundo, existe também um modelo de se explicar, uma fôrma como dissemos, na qual se encaixam as mais diversas discussões. Influente não só na economia como nas outras formas de conhecimento, é esse padrão da construção o saber, nas mais diversas áreas, que Foucault (1989) quer abarcar sob a categoria de episteme. Segundo suas próprias palavras:

"É com base nessa ordem [a episteme], assumida como solo positivo, ${ }^{21}$, que se construirão as teorias gerais da ordenação das coisas e as interpretações que essa requer. Assim entre o olhar já codificado e o conbecimento reflexivo bá uma região mediana que libera a ordem no seu ser mesmo: e ai que ela aparece, segundo as culturas e segundo as épocas, contínua ou graduada, fracionada ou descontinua, ligada ao espaço ou constituida a cada instante pelo impulso do tempo, semelhante a um quadro de variáveis ou definida por sistemas separados de coerências, composta de semelhanças que se aproximam sucessivamente ou se espelham mutuamente, organizadas em torno de diferenças crescentes, etc. (...) Assim, em toda cultura, entre o uso do que poderia se chamar os códigos ordenadores e as reflexões sobve a ordem, há a experiência nua da ordem e de seus modos de ser." (Foucault, 1989, p. 11).

21 Poderíamos razoavelmente traduzir essa expressão por "condições de possibilidade". 
Estudando em sua obra "As Palavras e as Coisas" o surgimento e a evolução da gramática, da biologia e da economia, Foucault desvenda que ordens são essas. É como se só fosse possível aos homens de um tempo, mergulhados que estariam num mundo dominado por um modo específico de positividade, edificar o conhecimento por meio de uma episteme peculiar.

É um conceito difícil, ainda mais soterrado nas expressões filosóficas e no modo semiartístico de escrita de seu criador. Mas é plausível entender essa categoria como um arquétipo, uma forma que os pensadores têm, em determinado tempo, de perceberem as semelhanças, estabelecerem as classificações, de se perguntarem e se responderem de forma objetiva. As condiçôes de possibilidade do conhecimento mudam com o tempo. Dois exemplos estudados por ele, tangentes à economia, parecem clarear melhor o conceito.

Foucault destaca a diferença entre as teorias do valor de Smith (1723-1790) e de Ricardo (1772-1823) com referência às diferentes epistemes dos séculos XVIII e XIX. No primeiro desses séculos dominava a chamada episteme clássica, que surge no começo do século XVII, e que tem por tônica a "representação". A construção do conhecimento é feita a partir de comparações de dois tipos: a quantitativa e a qualitativa. Enquanto a primeira é usada sobre elementos mensuráveis, comparando-os em termos sempre de unidades comuns, a segunda classifica, faz taxonomias. Notar que a classificação está presente tanto nos elementos quantificáveis como nos que não se prestam a isso é essencial. Antes de aplicar as unidades é preciso categorizar, impor uma ordem. Em meio à elaboração dessa ordenação, numérica ou nominal, ainda temos que reconhecer o papel dos signos, ou seja, daqueles elementos que o saber toma como representação de um objeto qualquer. ${ }^{22}$ Nesse sistema de ordenação pela comparação, sempre era buscado um signo das coisas, algo que pudesse representar um objeto de análise. É nessa episteme, e por causa dela, que Foucault (1989, p. 179-181) fala da economia como análise das riquezas. Cita a preocupação dos economistas com a moeda, a representação por excelência da riqueza. E demonstra a preocupação deles com os mecanismos de troca, o comércio, como objetos primordiais dos fenômenos econômicos. Uma vez que a comparação era a positividade do conhecimento, é natural que estudar como as coisas se equivalem, e como esse sistema de equivalências era representado, fosse o centro do saber econômico. Estuda-se a moeda, versa-se sobre a prata e ouro, tecem-se consideraçôes sobre a quantidade de moeda e sua relação com o sistema de preços, que compara os representados e, mais ainda, enfatiza-se o comércio como a atividade econômica por excelência. Smith, tributário dessa episteme clássica, embora Foucault (1989, p. 240) o veja como intelectual de transição em direção às or-

22 Signo é uma palavra que pode ter seu significado aproximado por "representar algo diferente de si mesmo". Isto quer dizer que o signo é em si um ser, uma entidade, mas ao mesmo tempo ele serve de representação para seres diferentes de si. 
dens do século XIX, funda sua teoria do valor sob a égide dessa maneira de construir o conhecimento. Em Smith, afirma Foucault, o trabalho confere valor às mercadorias não porque há um primado da produção ôntico em suas idéias, mas porque serve de unidade de medida. Representa, enfim. E a análise da produção, que vai ser o escopo principal dos economistas que trabalharão sob a episteme da economia política clássica, entra em Smith apenas como uma conseqüência. A divisão do trabalho, que talvez ao lado do estudo do valor seja o ponto que mais interessou aos economistas em sua obra, é dada em função da extensão do mercado, das trocas, portanto. Diz Foucault (1989, p. 238): "As necessidades e a troca de produtos que podem responder a elas são sempre o princípio da economia: são seu primeiro motor e a circunscrevem; o trabalho e a divisão que o organiza não passam de seus efeitos."

No período seguinte, a economia de Ricardo concentra-se sobre a produção. Foucault novamente vê isso como resultado da episteme na qual esse autor estava imerso. No último lustro do século XVIII já era possível perceber uma mudança nas ordenações que conferem positividades ao conhecimento. (Foucault, 1989, p. 235). Comparar por meio de signos que representem um objeto não é mais a forma do conhecimento, agora ocupa seu lugar a história, a série causal. Os elementos são organizados em seus pontos no tempo que se desenrola historicamente, num acúmulo de determinações em que deságuam seus efeitos. Conhecer significa colocar os acontecimentos, os objetos designados pelas categorias que surgem numa narrativa temporal. O que Ricardo nos apresenta em seus "Princípios de Economia Politica e Tributação", de 1817, parece encaixar-se nessas novas condições de possibilidade. Foucault (1989, p. 269) nos explica:

"A diferença, porém, entre Smith e Ricardo está no seguinte: para o primeiro, o trabalbo, porque analisável em jornadas de subsistência, pode servir de unidade comum a todas mercadorias (de que fazem parte os próprios bens de subsistência); para o segundo a quantidade de trabalbo permite fixar o valor de uma coisa, não apenas porque este seja representável em unidades de trabalho, mas primeiro e fundamentalmente porque o trabalho é 'a fonte de todo o valor'."

Pensar a partir da produção é a inserção da história no pensamento econômico, é organizá-lo por ela. É muito interessante a interpretação de Foucault, na medida em que Ricardo, um economista tido como pioneiro nas abstrações e deduções aistóricas, transforma-se no pioneiro da economia sob essa nova episteme, marcada pela historicidade. O trabalho é a fonte de valor porque a história do homem mostra sua luta constante pela sobrevivência, só foi preciso trabalhar na acepção moderna "no dia em que os homens se acharam numerosos demais para poderem nutrir-se dos frutos da terra." (Foucault, 1989, p. 271). Essa natureza avara, que tem seu ponto alto em Thomas Malthus (1766-1834), coloca a história do homem num desenrolar finito. A renda 
fundiária aparece porque cada vez terras mais improdutivas têm que ser trabalhadas, e juntamente com as rendas aumentam os custos de produção. Salários precisam subir a fim de fornecer aos trabalhadores os meios de vida, e em conseqüência os lucros baixam. Numa situação em que os lucros sejam tão baixos que não façam contrataremse novos trabalhadores, a falta de remuneração adicional da mão-de-obra restringe o crescimento da população, o sistema atinge um equilíbrio. Sem a necessidade da abertura de novas fronteiras agrícolas a economia chega a um ponto de estagnação. É importante notar a simetria que essa episteme tem em Marx. Foucault (1989, p. 276) coloca que a solução de Marx é contrária, mas baseada na mesma historicidade de pensamento. Nele a história tem papel negativo, desnuda e reforça as contradições existentes nos fenômenos econômicos até o ponto de ruptura, a partir do qual a economia não seria mais perpassada por contradições.

Dados os exemplos acima, restam-nos dois comentários essenciais à utilização da categoria sugerida por Foucault. Primeiro é necessário reconhecer que esse autor não aponta origens das referidas epistemes, muito menos o porquê das mudanças que ocorreram nos séculos XVII e XIX. Foucault parece se esquivar de uma resposta por duas vezes: tanto quando comenta o primeiro ponto de mudança quanto no segundo. Resta-nos apenas a afirmação citada anteriormente de que "ela aparece segundo as culturas e segundo as épocas", deixando bastante a desejar nesse sentido. Foucault chama seu método de arqueologia do conhecimento, ou seja, ele estaria interessado em descobrir as práticas, que no caso em tela são os moldes, as positividades do conhecimento de determinada época. Não lhe interessa, ou parece que a dificuldade de se explorar o surgimento de epistemes não vale o esforço. Mais uma vez em suas palavras: "A arqueologia deve percorrer o acontecimento segundo sua positividade manifesta." (Foucault, 1989, p. 232). Embora a busca de raízes para as condições de possibilidade seja uma questão extremamente interessante, não obtemos resposta. Basta reconhecer sua existência, utilizá-la como categoria que atenua o anacronismo, pois nos coloca mais perto das maneiras de conduzir o conhecimento em outras épocas.

Em segundo lugar é mister advertir que as epistemes descritas por Foucault, como a clássica, dos séculos XVII e XVIII, e a moderna, constituída a partir do XIX, podem não abraçar por completo obras de autores de culturas e lugares distantes dos analisados por Foucault. Um exemplo interessante é o do filósofo italiano Giambatistta Vico (1668-1744), que no final do século XVII estava em pleno descompasso com o cartesianismo de seu tempo. Os alemães, que fundaram a escola historicista, também têm muito das suas influências enraizadas sobre ideários marginais em relação ao cenário anglo-francês no qual Foucault se concentra. Sendo assim, sugere-se aqui que as investigaçóes futuras, embasadas no modelo proposto aqui, sirvam também de análises sobre a coexistência de epistemes numa mesma época, uma hipótese que 
parece razoável, uma vez que a arqueologia de Foucault pode não ter escavado todos os "sítios" do pensamento humanístico do século XIX.

\section{O Modelo em Sintese}

A Figura 1 pretende ser um resumo do que estamos propondo como modelo interpretativo ou protocolo de leitura do contexto da descoberta em ciência econômica. Retratamos a possibilidade da existência de várias epistemes num mesmo período histórico, embora admitamos que sempre há um mainstream para as positividades do conhecimento humano. Dentro de cada episteme está representada a pluralidade a que está aberto o pensamento dentro dessas mesmas ordens, como deixou claro o exemplo de Foucault sobre as similitudes entre Ricardo e Marx. As escolas de pensamento estão caracterizadas como PPCs, com seus núcleos duros e cinturões protetores, lembrando ainda que as heurísticas, por sugestão de Backhouse (1998), também devem ser incluídas como elementos sobre os quais não se aplica o modus tollens. Ainda a caracterização por meio da descrição lakatosiana não é excludente, como já foi destacado, em relação ao modelo de Kuhn, ou seja, as escolas de pensamento também podem ser pensadas como conjuntos de matrizes disciplinares e exemplares.

Em síntese, é necessário, como passo mais importante no estudo do contexto da descoberta em economia, reconhecer a unicidade da realidade social específica. Sendo assim, assume-se também que sua apreensão só é possível por meio das já discutidas visões de mundo, isto é, não há uma maneira de conhecer o entorno social de forma neutra, sem emitir opinião sobre ele. A tese da dependência da teoria, que implica a consideração das visões de mundo, deve ser considerada em algum grau. São justamente essas impressões interessadas da realidade que provocam rupturas, diferenças e pluralidade nas abordagens econômicas. As thematas, por sua vez, mesmo sendo princípios que transcendem o tempo em que surgiram, parecem vir à tona, no pensamento em economia, a partir de idéias fundadas sobre visões particulares da realidade, ou seja, a partir das ideologias. É assim que o atomismo serve de themata para o pensamento neoclássico, ao se postar como alternativa de reforma social dentro do capitalismo, valorizando o indivíduo, como já destacado no comentário sobre as idéias de Walras. A dialética de Heráclito, themata opositora do seu par dicotômico formulado por Parmênides, argumentando sobre a efemeridade do ser, serve a Marx como pilar de seu método histórico, que deságua na mudança do modo de produção. No mesmo sentido, o mainstream atual vive um recrudescimento da themata de Galileu, procurando uma legitimação social a partir da absorção dos métodos matemáticos das ciências naturais. Por último deve se destacar a necessidade da adequação dessas thematas às epistemes de cada época. Elas têm que fazer sentido naquilo que Foucault chama de sistema de positividades de uma cultura, de um tempo. No exemplo dado 
acima pode-se reconhecer a presença de uma themata sobre a ordem espontânea nos fenômenos econômicos, uma tendência ao equilíbrio, e sua adequação tanto ao pensamento smithiano quanto ricardiano, ou seja, sob duas epistemes diferentes. Thematas podem ultrapassar epistemes, embora só sejam utilizadas quando fazem sentido sobre as positividades determinadas por essas últimas.

\section{FIGURA $I$ - REPRESENTAÇÃO ESQUEMÁTICA DO MODELO INTERPRETATIVO}

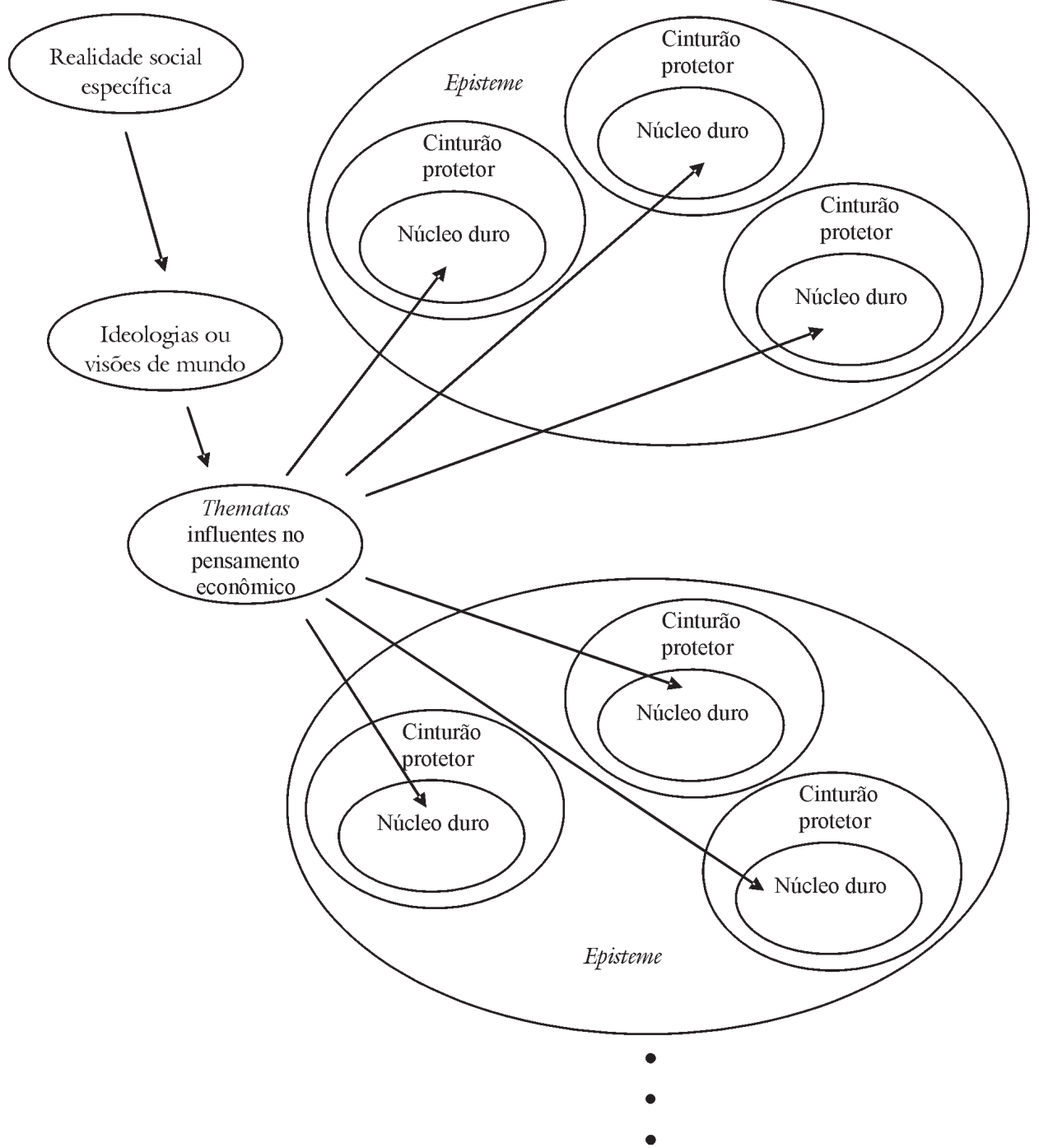




\section{CONCLUSÃO}

É importante ressaltar que o modelo interpretativo sugerido acima foi esboçado a partir de reflexões sobre a história do pensamento econômico, não tendo maiores pretensões filosóficas. Deve-se também advertir o leitor que as categorias analíticas utilizadas aqui, bem como a compatibilização entre elas, respondem a uma visão particular da história do pensamento econômico, que tem como mote o aspecto plural dessa área do conhecimento humano. Nessa linha de raciocínio, um dos objetivos mais interessantes a se perseguir, tanto na metodologia da economia quanto na historiografia da disciplina, é a insistência nesse caráter de diversidade teórica. Rejeita-se a existência de qualquer programa de pesquisa redentor, que possa dirimir os desacordos e reunir em torno de si a totalidade dos economistas. Mais ainda, pensar sobre o modo correto de fazer economia é uma questão que se coloca ou no nível instrumental, isto é, para evitar contradições internas, mau uso de dados e de técnicas estatísticas, ou para garantir aquilo que Jürgen Habermas chamou de sprachetik. Neste sentido, então, é preciso ultrapassar o positivismo que ainda permeia as idéias de muitos economistas que não acompanham as discussões sobre o método, e partimos do pressuposto que isso exige a articulação em torno desse pensamento tolerante. É necessário, portanto, como o ensaio acima pretendeu fazer, debater interpretações sobre "como os economistas discordam”.

\section{REFEREANCIAS BIBLIOGRÁFICAS}

Alencar, E. Introdução à lógica matemática. São Paulo: Makron Books, 1992.

Backhouse, R. Explorations in economic methodology: from Lakatos to empirical philosophy of science. London: Routledge, 1998.

Barnes, B. Scientific knowledge and sociological theory. London: Routledge \& Kegan Paul, 1974.

Blaug, M. Metodologia da economia: ou como os economistas explicam. São Paulo: EDUSP, 1993.

. No history of ideas, please, we're economists. Journal of Economic Perspectives, v. 15, n. 1, 2001.

Bloor, D. Science and social imagery. London: Routledge \& Kegan Paul, 1976.

Caldwell, B. Beyond positivism: economic methodology in the nineteenth century. London: George Allen \& Unwin, 1982.

Coats, A. W. Is there a "structure of scientific revolutions" in economics? Kyklos, v. 22, 1969. 
De Marchi, N. Introduction. In: De Marchi, N., Post-Popperian methodology of economics: recovering pratice. Boston: Kluwer, 1992.

Dobb, M. Theories of value and distribution since Adam Smith: ideology and economic theory. New York: Cambridge University Press, 1973.

Dow, S. The methodology of macroeconomic thought: a conceptual analysis of schools of thought in economics. 2a Edição. Cheltenham: Edward Elgar, 1996.

Earp, F. S. Um pouco além de Thomas Kuhn. Revista de Economia Política, v. 16, n. 1 (61), 1996.

Febvre, L. El problema de la incredulidad em siglo XVI: la religión de Rabelais. México: Uteha, 1959.

Feyerabend, P. K. Against method. 1ª Edição. New York: Verso Books, 1993.

Foucault, M. As palavras e as coisas. São Paulo: Martins Fontes, 1981.

Hands, W. Reflection without rules: economic methodology and contemporary science theory. New York: Cambridge University Press, 2001.

Heilbroner, R.; Milberg, W. The crisis of vision in modern economic thought. New York: Cambridge University Press, 1995.

Holton, G. A imaginação científica. (trad. port.). Rio de Janeiro: Zahar, 1979.

. Thematic origins of scientific thought: Kepler to Eistein. Ed. rev. London: Harvard University Press, 1988.

Keynes, J. M. A teoria geral do emprego, do juro e da moeda. São Paulo: Atlas, 1982.

Knorr-Cetina, K. The manufacture of knowledge. New York: 1981.

Kuhn, T. A estrutura das revoluções cientificas. $8^{\mathrm{a}}$ Edição. São Paulo: Perspectiva, 2003.

. Reflections on my critics. In: Lakatos, I.; Musgrave, A., Criticism and the growth of knowledge: proceedings of international colloquium in philosophy of science. London: Cambridge University Press, 1970a.

. Second thoughts on paradigms. In: Suppes, P. (ed.), The structure of scietific theories. Urbana: 1970b.

Lakatos, I. Falsification and the methodology on scientific research programmes. In: Lakatos, I.; Musgrave, A. Criticism and the growth of knowledge: proceedings of international colloquium in philosophy of science. London: Cambridge University Press, 1970. 1999.

. A história da ciência e suas reconstruções racionais. São Paulo: Edições 70,

Latsis, S. J. Method and appraisal in economics. New York: Cambridge University Press, 1976.

Lawson, T. Reorienting economics. London: Routledge, 2003. 
Loasby, B. J. Public science and public knowledge. Research in the History of Economic Thought and Methodology, v. 4, 1986.

Mäki, U. Social conditioning of economics. In: De Marchi, N., Post-Popperian methodology of economics: recovering pratice. Boston: Kluwer, 1992.

Mastermann, M. The nature of a paradigm. In: Lakatos, I.; Musgrave, A., Criticism and the growth of knowledge: proceedings of international colloquium in philosophy of science. London: Cambridge University Press, 1970.

Myrdal, G. Value in social theory: a selection of essays on methodology. London: Routledge \& Kegan Paul, 1958.

Paula, J. A. et al. Nações e estilos de economia política. Textos para Discussão, n. 160. Cedeplar/UFMG, 2001.

Paula, J. A. Walras no Journal des Économistes: 1860-65. Revista Brasileira de Economia, v. 56, n. 1, 2002.

Peacock, M. Explaining theory choice: an assessment of the critical realist contribution to explanation in science. Journal for the Theory of Social Behaviour, v. 30, n. 3,2000 .

. No methodology without ontology! Reorienting economics. Journal of Economic Methodology, v. 11, n. 3, 2004.

Peters, F. E. Termos filosóficos gregos. (trad. port.). 2a Edição. Lisboa: Fundação C. Gulbekian, 1983.

Popper, K. R. The logic of scientific discovery. New York: Harper Torch Books, 1968.

Robinson, J. Filosofia económica. Rio de Janeiro: Zahar, 1964.

Schumpeter, J. A. História da análise econômica. vol. 1. Rio de Janeiro: Fundo de Cultura, 1964.

Shapin, S. History of science and its sociological reconstructions. History of Science, v. $20,1982$.

Stengers, I. A invenção das ciências modernas. São Paulo: Editora 34, 2002.

Viera, J. G. S.; Fernandez, R. G. A estrutura das revoluções cientificas na economia e a revolução Keynesiana. 2004. Mimeografado.

Viskovatoff, A. Rationalism and mainstream economics. Journal of Economic Methodology, v. 10, n. 3, 2003.

Whitley, R. The intellectual and social organization of the sciences. Oxford: Oxford University Press, 1984. 